\title{
EL DRAMA Y SU INFLUENCIA EN LA OBRA TEMPRANA DE LUKÁCS
}

\section{DRAMA AND ITS INFLUENCE IN LUKÁCS'S EARLY WORK}

\author{
Diego Fernando Correa CASTAÑEDA* \\ UNED
}

\begin{abstract}
Resumen: El artículo realiza un acercamiento a las influencias que recibió el Lukács joven de algunos dramaturgos: Shakespeare, Ibsen, Strindberg, Hebbel, Shaw, etc. En dichas influencias están contenidas las primeras huellas del rechazo hacia la burguesía, los primeros conatos de aspectos revolucionarios y la posterior inclinación hacia la estética y la ética. Se destaca de manera clara los giros que Lukács da a lo largo de su vida intelectual, vida que estuvo marcada por la influencia de autores diferentes en las respectivas épocas. Se hace énfasis en aspectos tales como la teoría del reflejo, la periodicidad, el dinero, la singularidad privada, la soledad, la relación del público y la presencia de Dios en el drama. En términos generales, podría decirse que la influencia que recibió Lukács por los autores citados fueron fundamentales para el posterior desarrollo de su obra.
\end{abstract}

Palabras clave: Dramaturgos, aspectos revolucionarios, estética, teoría del reflejo, periodicidad, dinero, singularidad privada, Dios.

AвSTRACT: This article details the influences Lukács received from some playwrights: Shakespeare, Ibsen, Strindberg, Hebbel, Shaw, etc. Those influences contain the first traces of his rejection to the middle class, the first revolutionary movements and later inclination towards aesthetics and ethics. The twists Lukács had during his intellectual life clearly stand out, a life that was touched by the influence of different writers in their time. It emphasizes aspects such as the reflection theory, periodicity, money, private singularity, loneliness, the connection of the public and the presence of God in the drama. In general terms it could be said that the influence Lukács received from these authors was fundamental for the development of his work.

KeYwords: Playwrights, revolutionary moments, aesthetic, reflection theory, periodicity, money, private singularity, God.

\footnotetext{
* Diego Fernando Correa Castañeda. Universidad Nacional de Educación a Distancia. Doctor en Filosofía de la UNED. liferco@hotmail.es Neschwitzweg 29. Grimma. Deutschland.
} 


\section{Introducción}

Lukács fue un ferviente admirador de Shakespeare, Ibsen, Strindberg, Hebbel, Shaw, entre otros. Las influencias que ejercieron estos artistas sobre su pensamiento se encuentran diseminadas por toda la obra de Lukács. En primera instancia, la mayor influencia la recibió en los escritos de juventud, pero los tentáculos de las posiciones adoptadas por estos dramaturgos llegan hasta la producción madura de nuestro autor. Es por este motivo que se estudiará en un principio las primeras obras de Lukács, entre las que se encuentra Sociología de la literatura y El alma y las formas. Es importante resaltar que Lukács da, en muchas ocasiones, un giro respecto a las posiciones que había adoptado en su juventud. Dicho giro se hace muy evidente en algunos aspectos destacados de su producción madura, por ejemplo, en la forma repetitiva o no de caracteres en las obras, en la influencia o no de los aspectos económicos en el desarrollo de la producción artística, en el papel que juega el pasado en la utilización de viejas nociones en las producciones presentes, en el azar en el desarrollo de la creación, en la presencia de la figura divina en la escena en la que se desarrolla el drama de la humanidad y en la posterior suplantación del poder de la religión en esta producción. Como se puede ver el campo de estudio es grande.

Además de esto también se estudiará las obras de madurez en busca de estas mismas nociones: Aportaciones a la historia de la estética, la Estética, Prolegómenos a una estética marxista, Significado actual del realismo crítico, entre otras. En estas obras están contenidos los giros mencionados anteriormente y, desde luego, las nuevas propuestas impulsadas por Lukács en busca de la superación y el esclarecimiento de lo que en un principio parecía oscuro. La primera gran contradicción con la que se enfrentó Lukács quizás sea la adoptada frente a la relación que hay entre la producción artística de una época y sus respectivas relaciones económicas. Lukács escribió con veinticuatro años una obra en húngaro que nunca fue traducida al alemán, pero sí al español: Evolución histórica del teatro moderno, integrada en el libro Sociología de la literatura, por Peter Ludz, con el nombre de Historia evolutiva del drama moderno. Lukács comienza dicha obra hablando sobre las implicaciones sociológicas que tiene todo campo de estudio. Pero a su vez, lanza un severo reproche al método utilizado por esta crítica sociológica, que no es otro que vincular los fenómenos sociales a sus respectivos condicionamientos económicos. Ante este hecho, Lukács toma posición con afirmaciones como ésta: «el defecto mayor de la crítica sociológica del arte consiste en que busca y analiza los contenidos de las creaciones artísticas, 
queriendo establecer una relación directa entre ellos y determinadas condiciones económicas» (Lukács, 1968a: 67).

Es palpable que aquí Lukács, aunque se deja entrever que ya conoce el marxismo, aún no ha asumido plenamente la concepción dialéctica de la realidad. En el texto se ve claramente el rechazo a vincular las creaciones artísticas con las condiciones económicas que les dan forma o, mejor dicho, que las hacen posibles. Por aquella misma fecha comienza el interés de Lukács por Ibsen, del que Kadarkay da testimonio al decir: «podemos trazar a través de su vida los movimientos que le llevarían desde visitar a su ídolo Ibsen en Noruega siendo estudiante...» (Kadarkay, 1994: 14). ¿ Será que esa primera y temprana aproximación a Ibsen había emanado de su vivo interés por conocer a quien tan bien estaba reflejando su propia condición social? De ahí que haya resultado tan importante la puesta en marcha del «...proyecto teatral Thalia: ... [en donde se pusieron en escena obras de] Ibsen, Hebbel y Strindberg... [las cuales mostraban], la escenificación de la existencia humana en el sinsentido del mundo» (Surghi, 2015: 41). Además, hay un hecho histórico relevante: Lukács nació en 1885 e Ibsen murió en 1906. Si tenemos en cuenta que Ibsen sufrió en el año 1900 un primer ataque de apoplejía, nos estamos situando en un Lukács con unos quince o dieciséis años. No es de extrañar que su principal preocupación fuera la relación con sus padres, y que -la supuesta visita a Ibsenfuera, como se dijo anteriormente, solo para conocer a la persona que tan fielmente estaba reflejando su propia condición vital. A esto hay que sumarle que lo que Ibsen estaba haciendo era cuestionar el modelo de familia y sociedad dominante de la época.

\section{Primeras aproximaciones}

Aunque las reflexiones de Lukács en torno a los orígenes de la tragedia dan comienzo con la imponente figura de Homero (Lukács, 1999: 55), en donde la sociedad se mueve todavía con parámetros colectivos, sociales, comunales - esto es, aún no trágicos, individualistas- será la Poética de Aristóteles la obra paradigmática en la orientación para desarrollar todos los presupuestos de esta. Por ello vamos a detenernos un momento en lo que dice el estagirita, y así ver con mayor detalle la influencia que tuvo sobre casi la totalidad de la producción dramatúrgica del periodo tratado. Aristóteles se pregunta: ¿qué es lo que han 
de pretender y qué deben evitar los que componen los argumentos?, ¿de dónde se obtendrá el efecto propio de la tragedia? Y responde de la siguiente manera.

Pues bien, dado que la composición de la tragedia más hermosa no debe ser simple, sino compleja, y ésta ha de imitar las acciones que inspiren temor o compasión (pues esto es lo propio de una imitación de tal naturaleza), en primer lugar, lo que está claro es que ni los hombres buenos deben aparecer pasando de la dicha al infortunio (pues esto no inspira ni temor ni compasión, sino repulsa), ni los malos, del infortunio a la dicha (pues esto es lo menos trágico de todo, ya que no tiene nada de lo requerido, pues no es ni humano, ni compasivo ni terrible); ni tampoco debe ser sumamente malo caer de la dicha en la desdicha, porque tal trama podría despertar sentimientos humanitarios, pero no compasión ni temor, ya que, por una parte, uno se fija en aquel que sin merecerlo es desafortunado; y por otra, en el que es semejante a nosotros. Compasión se tiene del que no merece su infortunio, y temor, del semejante, de modo que lo que ocurra no inspirará ni compasión ni temor. Queda, pues, el personaje intermedio entre los mencionados. Y es aquel que no destaca ni por su virtud ni por su justicia, y tampoco cae en el infortunio por su malicia o maldad, sino por algún fallo; siendo de aquellos que gozan de gran reputación y felicidad, como Edipo y Tiestes y hombres ilustres de tal alcurnia (Aristóteles, 2006: 63-64).

Las esferas centrales con las que interactúa Lukács se mueven dentro de las categorías y aportes realizados por Aristóteles. Así éstos ya hayan sufrido algún tipo de mutilación y hayan sido llevados al presente con un nuevo ropaje: «...[la] teoría dramática aristotélica reinterpretada, o sea... la tragedia burguesa» (Lukács, 1966a: 509). Es en este terreno en el que se lleva a cabo la confrontación entre los tres tipos de comportamiento humano.

La transformación que efectúa la orientación al valor estético dentro del sujeto es, pues, una transformación que preserva su subjetividad... convierte al sujeto natural en un sujeto estilizado que, en contraposición con el sujeto construido de la lógica y con el postulativo de la ética, es una unidad viva que comprende la plenitud de contenido de las vivencias; una unidad que abarca la totalidad de la humanidad (Lukács; 2015b: 211).

Las especulaciones sobre el lugar que ocupan tan importantes disciplinas: la estética, la lógica y la ética, ya eran evidentes en el Lukács de Acerca de la pobreza de espiritu (1912). De ahora en adelante la lucha que establece el hombre sobre 
las dimensiones sociales en las que se moverá, quedarán fijadas en las formas de refiguración artísticas con las que lo representará. La categoría del tertium datur (Lichtheim, 1973: 98-99) alcanza un nuevo nivel. Para Aristóteles debería existir un personaje intermedio, la práctica era la mediación entre el sujeto y el objeto, el reflejo pavloviano ocupaba el espacio central entre el reflejo científico y el estético, ahora el ensayo quedará ubicado entre la ciencia y el arte. (Surghi, 2015: 37 y ss.). Recordemos que el ensayista -Lukács era un ensayista-, en contraposición con el poeta, es un generador de juicios de valor. «¿Quién le da esa autoridad jurídica... [al ensayista?] ... pues sin duda se crean en el ensayista mismo sus criterios de juicio» (Lukács, 2013: 59). De esta manera podemos ver que dentro de estas esferas lo que más le preocupaba, en última instancia, era la dimensión del valor. El lugar, el papel y las influencias que ocuparía dicha forma de actuación humana dentro del individuo, o para llamarlo con palabras de Lukács, del sujeto.

Podría decirse que en Lukács las disciplinas que mayor influencia ejercieron en su temprano desarrollo -la ética y la estética- tuvieron un desarrollo paralelo. Así en un principio se haya preocupado más por la ética, ésta siempre creció en compañía de su otra hermana gemela.

Lukács decía que la apuesta de Fausto con Mefistófeles era una apuesta sobre "diferentes" conceptos de vida. Mefistófeles le ofrece a Fausto los placeres sensuales de la vida. Pero Fausto, en realidad, está pensando en algo "más elevado". Como dijo Lukács, en servir a la humanidad (cit. en Kadarkay, 1994: 778).

Pero aún dentro de esta duplicidad de intenciones, Lukács reclamó en algún momento ante sus oponentes, que le permitieran tener dos almas como se le permitió a Fausto (Lukács, 1985: 12). Lukács sufrió en su juventud todos los avatares que estaban asolando a la sociedad húngara en particular y a la europea en general. Le tocó desarrollar, yendo a la deriva, su temprana vocación estética junto con presupuestos éticos, los cuales tenían como objetivo marcar distancias con la decadente clase social a la que él pertenecía y que mejor conocía: «Lukács se sentía espiritualmente a la deriva en una época en que la civilización burguesa -la única que había comprendido y apreciado- comenzaba a desintegrarse» (Lichtheim, 1973: 55). Es de esta manera como hemos sabido que las influencias tuvieron varias vías de penetración. De haber sido Lukács un burgués comprometido se hubiera basado quizás solo en presupuestos estéticos, más que todo en las obras de los dramaturgos que se representaban por la época: Ibsen, Strindberg, 
Shaw, Hebbel etc. Pero no fue así, Lukács se vio arrastrado por la nueva corriente que reclamaba cambios sociales profundos.

El antiguo régimen estaba llamado a desaparecer y Lukács, además de esta poderosa fuerza, comenzó a sufrir los golpes que también te da la vida real, en este caso, su relación con Irma Seidler. De ahí que la primera aproximación ética vino marcada por su relación con ella, con Leo Popper y con Béla Balázs. Relaciones que dejaron una profunda huella en los sentimientos de Lukács. Así quedó anotado en el Diario 1910-1911 encontrado en 1973, dos años después de su muerte, en una caja fuerte de un banco de Heidelberg: «El diario revela los dramas y deseos del autor, su permanente miedo a la frivolidad y, sobre todo, la tremenda crisis que le causó la muerte de su amiga Irma Seidler» (Lukács, 1985a: 138 y ss. $)^{1}$. El interés de Lukács por la ética tenía una génesis personal y no social. Estamos hablando de un Lukács anterior a 1915: «Vale la pena destacar que Lukács hizo su primer acercamiento positivo a Marx en 1915» (Kadarkay, 1994: 274). Además, él mismo afirma que en los años de juventud cuando aún estaba estudiando en el Gymnasium ya había tenido acercamiento a obras como el Manifiesto Comunista y el primer tomo del El Capital:

Estas lecturas... [el Manifiesto comunista, el 18 Brumario, el Origen de la familia, etc.] me dejaron convencido de su verdad en lo que respecta al meollo del marxismo. Me impresionó ante todo la teoría de la plusvalía, la concepción de la historia como historia de la lucha de clases y la división de la sociedad en clases. Pero como es habitual en un intelectual burgués, limité esta influencia a la economía y ante todo a la Sociología (Lukács et al., 1978: 129).

Una vez demostrado que Lukács ya tenía conocimientos sobre marxismo resulta extraño que sus primeras inquietudes tuvieran motivaciones más bien peregrinas. «A pesar de la indignada actitud de Lukács hacia su clase, no mostraba ningún "serio" interés por Marx" (Kadarkay, 1994: 35). Como lo demuestra el mismo Lukács al negarse a vincular la esfera económica con el desarrollo de los demás aspectos sociales. En especial con el mundo de la creación de obras de arte, el cual recibía la influencia del desarrollo económico a través de un opaco cristal. «La acción de las circunstancias económicas sobre la obra de arte sólo es indirecta» (Lukács, 1968a: 69). El poder de los diferentes sistemas filosóficos hizo

\footnotetext{
1 Luis Meana. 1991. Georg Lukács, diario de una crisis. https://elpais.com/diario/1991/08/12/ cultura/681948001_850215.html (03/09/2017)
} 
que Lukács, en sus inicios, no supiera muy bien hacia dónde dirigirse, de ahí este profundo y hermoso reclamo que les dirigía a sus opositores.

Si se permitió a Fausto abrigar dos almas en su pecho, ¿por qué no va a ser posible comprobar en un hombre por lo demás normal, pero que, en medio de un mundo en crisis, salta de una clase a la otra, en funcionamiento simultáneo y contradictorio de tendencias espirituales contrapuestas? (Lukács, 1985a: 12).

Lukács se mueve dentro de un ámbito en el que tanto la ética como la estética deberían gozar de una perfecta sintonía entre sí -esto nos llevaría nuevamente por el camino de su relación con Kant y Kierkegaard-. Es por este motivo, que a la vez que veía en las obras de Dostoievski -que igual que él parecía también tener dos almas- al nuevo Homero, tomaba de sus obras los elementos éticos que necesitaba para justificar los problemas por los que atravesaba, que como ya se dijo anteriormente, tuvieron la forma de relaciones humanas individuales. «Tras la muerte de Irma, en 1912, Lukács había comenzado a aproximarse más y más a Kierkegaard y a Dostoievski, los "dioses" rivales de la moralidad kantiana” (Kadarkay, 1994: 239). La incertidumbre del Lukács de la primera etapa queda también reflejada en estas palabras de Yvars: «Eticismo o esteticismo; Kant o Dostoievski» (cit. en Lukács, 1985a: 17).

Para el Lukács de El alma y las formas (1910) es ésta última, la forma, la que tiene mayor importancia. Dar forma se va convirtiendo lentamente en uno de los pilares de su monumental Estética: «La forma es el juez supremo de la vida. El poder dar forma es una fuerza juzgadora, algo ético, y en toda configuración está contenido un juicio de valor» (Lukács, 2013: 268). Dar forma artística es algo ético, de ahí que por necesidad tenga un fuerte componente de valor. Si esto es así, queda excluida la posibilidad de la distancia ética y estética con el objeto de la historia humana: la mercancía, de la cual, entre otras cosas, es de dónde tiene que salir el verdadero juicio, tanto ético como estético (Jaime Moreno) ${ }^{2}$. En este caso Lukács parece dar prioridad a la esfera de la moral, sin la que una obra de arte parece que dejaría de serlo:

2 Jaime Moreno (n. 1945). Filósofo colombiano. Estas aportaciones han sido elaboradas a través de las diversas entrevistas que he tenido con el filósofo Jaime Moreno. De ahora en adelante me referiré a él como (J. M). 
Lukács pone un enorme énfasis en la exploración de los aspectos morales de problemas de estética o de filosofía general. Es significativo que su monumental Estética -llena, por todas partes, de referencias morales- alcance su clímax en el capítulo sobre (La fuerza liberadora del arte)... no es, pues, sorprendente que, para Lukács, una obra de arte desprovista de significación moral no puede tener una importancia artística permanente (Mészáros, cit. en 1973: 68).

También es de destacar que estos aportes de Mészáros se quedan en el vacío al ser estudiada a fondo la Estética de Lukács y no haber sido detectada la tan grande influencia de los aspectos morales. Esta aproximación a los aspectos más destacados de la investigación -la esfera ética y la estética- y su posterior puesta en marcha por parte de Lukács, al vincularla directamente con la producción artística, ha generado que Lukács llegue al firme convencimiento que: «Si el arte pudiese conceder forma a la vida, si la bondad pudiese convertirse en acción, seríamos dioses» (Lukács, 2015b: 165). Siendo ésta una nueva prueba de la fusión e importancia de las dos esferas dentro del desarrollo de la categorización lukácsiana surgida de la problemática de lo trágico. Además de que también se van haciendo evidentes los pormenores del futuro cambio dado por Lukács, así como también los pasos que él siguió en las conexiones que estableció entre ambos campos del comportamiento humano. Kant y Kierkegaard son las dos figuras más destacadas en lo concerniente a la moral y a la estética. Dostoievski juega quizás el papel mediador en la recepción de ambas disciplinas.

\section{Budapest en la época de Lukács}

No se trata de hacer un recorrido histórico exhaustivo por toda la historia de la ciudad de Budapest, no es esa la misión de este artículo, sino solo mostrar algunos detalles, para hacer ver que la ciudad en la que Lukács desarrolló sus primeras inclinaciones filosóficas tenía una larga trayectoria, que a su vez iba a influir de manera notable en él. Budapest se había convertido en el siglo XV en uno de los centros de la cultura del Renacimiento humanista. El 29 de agosto de 1526 los otomanos vencen en la batalla de Mohács (Duby, 2007: 170-175), en 1541 la ocupan y ejercen el control de la región por un período aproximado de 150 años, hasta ser liberada en al año 1686. Después de este dominio la ciudad entró, entre los siglos XVIII y XIX, en una nueva era de prosperidad. Tras su unificación en 1873, se convirtió en una ciudad global. Poco antes de la unificación de las dos 
ciudades que hoy conforman la actual Budapest, la población de origen étnico húngaro superó a la alemana. Este fenómeno se debió a la migración masiva desde la superpoblada y rural Transdanubia y la gran llanura húngara. La proporción de judíos llegó a su punto máximo en 1900, es por este motivo que el Budapest de finales del XIX y principios del XX fue considerado la Meca judía. Entre toda esa inmensa masa de personas que se establecieron en la nueva y floreciente ciudad se encontraba «la abuela paterna [de Lukács], Judie Pollak... [quien] llegó a Hungría procedente de Galitzia con la primera oleada de inmigrantes judíos en los primeros años del siglo diecinueve» (Kadarkay, 1994: 22). Como se puede ver muy bien, la ciudad y la sociedad en la que Lukács estaba desarrollando su incipiente labor literaria, principios del siglo XX, tenía un recorrido histórico que la empujaba a realizar los cambios sociales que la nueva época demandaba.

\section{Situación familiar de Lukács}

Para describir claramente el escenario en el que el joven Lukács estaba desarrollando sus primeros contactos con el mundo social y cultural de su época acudo a lo expuesto por J. F. Yvars en el célebre Diario 1910-1911:

La sensibilidad intelectual, característica de la generación húngara de fin de siglo, ha sido calificada de anticapitalismo romántico. Quizás en el caso de Lukács las raíces del proceso de radicalización que había de conducirle al rompimiento con la cultura oficial presenten cierta tonalidad paradigmática (cit. en Lukács, 1985a: 15).

Además de todo esto tendríamos que tener en consideración que «a su remoto origen de judío asimilado, habría que añadir la beligerante apropiación paterna de los estímulos de ascenso y triunfo social peculiares de la incipiente burguesía industrial húngara» (1985a: 15), lo que le permitió viajar por toda Europa en busca de la tranquilidad necesaria para poder desarrollar todo su potencial creativo. Fruto de este esfuerzo surgió su primera y más importante obra temprana: El alma y las formas. Todas estas circunstancias reunidas produjeron inevitablemente una "constante invocación a la autenticidad por parte de la generación joven» (1985: 15a).

El principal motivo por el que Lukács buscó el acercamiento a los autores dramáticos viene derivado del conflicto que mantenía con su propio entorno 
familiar. Eran ellos los que le aportaban los elementos más próximos a la realidad para despejar las incógnitas ante las que él se debatía. Por esa época, principios del siglo XX, las teorías dominantes en este campo eran las de procedencia psicoanalítica -los diversos complejos expuestos por Freud (Freud, 2010: 27)-, o lo que Surghi denomina «la paradoja respecto a lo que el yo significa para la cultura centroeuropea» (2015: 51). Pero Lukács no aceptaba este tipo de argumentos para explicar la confrontación que se presentaba entre él y sus dos progenitores. Él estaría más de acuerdo con teorías que afrontaran esta confusa problemática desde otros puntos de vista. Por ejemplo, la posición de Félix Guattari: «El inconsciente se relaciona directamente con el campo histórico, económico y político más que con los referentes familiares y míticos que privilegia el psicoanálisis» (cit. en Martínez, 2008: 12). Arnold Hauser diría:

Freud, a consecuencia de su estricta concepción científica del mundo, es incapaz de apreciar los factores sociológicos en la vida espiritual del hombre, y aunque él discierne en el super-ego el representante judicial de la sociedad, niega al mismo tiempo que la evolución social pueda traer a nuestra constitución biológica e instintiva cambios esenciales (Hauser, 1967: 388).

Pero no es solo Lukács el que se opone a este tipo de teorías, también las encontramos de igual similitud en Thomas Mann.

Hay que llamar a las cosas por su nombre... En alemán lo demoníaco se confunde con lo impulsivo. Y lo que hoy ocurre es que los impulsos son explotados como medio de propaganda a favor de las más diversas doctrinas; más aún, los impulsos entran a formar parte de la doctrina. Se recurre a la psicología del impulso para remozar el viejo idealismo y darle una más profunda y atractiva realidad (Mann, 2009: 183).

El distanciamiento con la esfera psicoanalítica, para explicar su tensa relación familiar, le brinda además a Lukács la posibilidad de denunciar que la utilización de este tipo de teorías lo que buscan es distraer la atención de los verdaderos problemas sociales en los que sí se presentarían éstos de forma objetiva, que no serían de forma individual sino social. Jacobo Muñoz nos recuerda:

Son las clases sociales, los grupos humanos amplios, quienes toman consciencia de la necesidad de que se proceda a una transformación, a través de una experiencia cotidiana que les muestra la falta de adecuación de la forma en que está organizada la sociedad para responder a las nuevas exigencias 
que se le plantean; no es el individuo el que toma conciencia de unos problemas en cuanto afectan a sus intereses, es el grupo social el que reacciona a un problema colectivo e infunde a sus miembros unos talantes y actitudes concretos (Muńoz, 2010: 246).

\section{Describir la tragedia}

«El drama moderno es el drama de la burguesía; el drama moderno es el drama burgués» (Lukács, 1968a: 252). Es así como Lukács emprende la tarea de buscar los orígenes del drama moderno. Para él el origen de dicha forma de desarrollar el drama se encuentra en el período de esterilidad que siguió al declive presentado una vez terminado el renacimiento.

De momento solo queremos constatar que el nuevo drama se ha formado en la lucha por el drama burgués, lucha llevada a cabo en el período de esterilidad que siguió a la desfloración del drama del Renacimiento, del drama feudal y cortesano (Lukács, 1968a: 252).

El período renacentista fue muy fértil en todo tipo de nociones. No solo una nueva forma de representación dramática, sino también los primeros conatos en la representación literaria del hombre individual. Lukács exploró mucho estos terrenos y vio en Cervantes y Rabelais (Lukács, 2011: 48) a los artífices de esta separación. Todos estos cambios en la forma de reproducción de la realidad fueron los causantes de que se generara un nuevo suelo en el que levantarse. Quizás por eso «el nuevo drama fue producido por unas conscientes necesidades racionalistas y encontró un escenario completamente configurado y fortalecido por largas tradiciones» (Lukács, 1968a: 252). Si estos nuevos avances y logros produjeron un gran florecimiento y crecimiento en las refiguraciones artísticas de la realidad, no deja de ser cierto que muchos artistas -para Lukács especialmente, la vanguardia- volvieron nuevamente a caminar por los viejos caminos «el drama moderno es el primero y hasta ahora único drama que no ha nacido a partir de sentimientos místico-religiosos, que en el transcurso de su evolución posterior se acerca a lo religioso» (Lukács, 1968a: 252). Para Lukács lo más dramático de todo esto consiste en que presenta un retroceso con relación a la antigüedad, ya que «el drama antiguo... [supo desprenderse] paulatinamente de lo religioso» (Lukács, 1968a: 252). Lukács acusa de este tipo de comportamiento a la gran mayoría del arte vanguardista, convirtiéndose éste en otro de los motivos del distanciamiento 
que tuvo con gran parte de la intelectualidad europea de entonces, en especial con Ernst Bloch (Parkinson, 1973: 34).

Lukács reflexiona sobre la dualidad entre el drama antiguo y el moderno, de ahí que le resulte tan llamativa la pintura de Peter Bruegel el Viejo: «Lukács reverenciaba particularmente los pasajes de Bruegel, que muestran un mundo abandonado de Dios carente de significado" (Kadarkay, 1994: 135-136). Y es quizás este abandono lo que hace que el hombre sienta la necesidad de volver a buscar en el ya superado mundo suprasensible. Los antiguos lo sabían: el drama es escapar del destino al que nos tiene sometidos la trascendentalidad religiosa. Sería algo así como descubrir que somos prisioneros de un destino eterno e inamovible y que a la vez nos encontramos ante la imposibilidad de separarnos de él. Para Lukács es tan poderosa la fuerza del drama que llega a decir en El alma $y$ las formas: "Las relaciones entre los hombres no puede contener nada que no esté ya contenida rigurosamente en el complejo del drama» (Lukács, 2013: 200). La dualidad de esta problemática viene también determinada por la concepción de la vida que tenía el Lukács de la primera etapa. Si en El alma y las formas el hombre no sabía hacia dónde dirigirse, su vida no tenía sentido, para el hombre de Historia y consciencia de clase había llegado precisamente el momento de defender bajo todos los medios al nuevo hombre naciente (Lukács, 2014: 33).

\section{Diversas aproximaciones a la concepción de la tragedia}

«El carácter de lo trágico solo surge cuando el destino (lo no elegible por el hombre) siente la resistencia de la libertad y rebota sobre la fortaleza del héroe, aunque termine por aplastarlo» (Sánchez Meca, 1996: 461). La tragedia es una lucha entre dos cosas: en primer lugar, está el destino al que todos estamos predeterminados y luego el anhelo de libertad al que nos enfrentamos en nuestro afán por huir de ese destino impuesto. Lo trágico consistiría en esa lucha interna que el hombre siempre ha librado contra sí mismo. Mundo interior explorado por el primer Lukács «...en donde, como ensayistas y poetas, nos formamos en la soledad de nuestra interioridad» (Surghi, 2015: 43-44). Sin esta dialéctica de destino y libertad no existiría la tragedia. La libertad quizás llegue de la mano de la dialéctica materialista, herramienta que contribuirá de una manera notable a descorrer el velo que oscurece el horizonte, permitiendo ver con una nueva luz que la oscuridad de la tragedia es en parte la incapacidad humana para enfrentar la realidad. Incapacidad latente en la clase social llamada a liberar al hombre de 
las cadenas y la cual, ante su propia incapacidad, ha terminado cayendo en las manos del pesimismo.

Lo dicho puede aplicarse aún más directamente a esa herencia de la estética de la decadencia burguesa que es la supuesta vinculación de la tragedia con el pesimismo como concepción del mundo. Las filosofías de Schopenhauer y Nietzsche han formulado esa supuesta vinculación, y Wagner y Hebbel después de 1848, así como en la práctica dramática del Ibsen tardío, dieron mucho relieve a esa idea (Lukács, 1966a: 227).

1848 se convierte en la fecha clave para descubrir el camino de los sistemas filosóficos y literarios que se han alejado de lo humano. Aunque es cierto que, de Schopenhauer, Nietzsche y Hebbel esto resulta más claro, con relación al Ibsen tardío es Lukács el que lo hace evidente. De esta manera Lukács despeja las dudas de la presencia de la angustia en las obras tanto de Ibsen como de Strindberg. Dice Lukács que la angustia tiene:

Un efecto empobrecedor y deformador como factor dominante, y que además es utilizado de forma coercitiva sobre la imagen literaria del hombre y del mundo. La angustia se convierte en factor excluyente, eliminando del entorno todo lo que le pueda dar sentido y forma a la fisionomía social... [Es en este sentido que se trae a Strindberg a escena, del cual Lukács dice] ya existía en estado latente en el naturalismo, y culminó en el Strindberg de la última época (Lukács, 1984: 95).

Si aceptamos el hecho de que es la realidad social la que determina la consciencia, entonces nos encontramos ante el panorama de que a los creadores no les queda otra salida que adoptar dichos principios decadentes como modelo a refigurar. Ya que, como dice Marx en El Capital, «son formas mentales aceptadas por la sociedad, y por lo tanto objetivas» (Marx, 1975: 41). Ni siquiera se les puede culpar, al fin y al cabo, lo que están es reflejando la conciencia que hay en su época sobre la realidad, que como todos muy bien sabemos no es otra que la de la clase dominante, a la cual lamentablemente muchos grandes pensadores, quizás sin saberlo, han prestado sus servicios; no pudiendo escapar de una situación ante la que se sentían más que seguros. Esto les impedía morder la mano que los alimentaba. Más adelante se desarrollarán los aspectos revolucionarios de un verdadero artista cuando se enfrenta a la realidad deformada por la sociedad en la que le tocó en suerte vivir, pero de momento vamos a dejar que sea el 
propio Marx el que nos ilustre en este interesante debate. Así lo expone en $L a$ ideología alemana:

Las ideas de la clase dominante son, en cada época, las ideas dominantes, es decir, la clase que es el poder material dominante de la sociedad es, a la vez, su poder inmaterial dominante. La clase que dispone de los medios para la producción material dispone con eso, a la vez, de los medios para la producción intelectual (Marx, 2010: 98).

\section{Sobre la influencia de los dioses en el drama}

El drama es una representación; una representación del hombre y del destino; cuyo espectador es Dios. Es solo espectador, y nunca se mezcla su palabra ni su gesto entre las palabras o los gestos de los que representan. Solo sus gestos descansan en ellos. "El que mira a Dios muere», escribió una vez Ibsen; pero ipuede vivir aquel sobre el cual cae su mirada? (Lukács, 2013: 241).

El interrogante que Lukács plantea tiene diversas maneras de afrontarse. Entre la más llamativa se encuentra la manifiesta similitud que él cree ver entre él mismo y Kierkegaard. Si Kierkegaard creía haberse sentido elegido por Dios -mirado por él-y por este motivo se distanció de Regina Olsen -Kierkegaard siempre se creyó el nuevo Abraham-, Lukács por su parte se distanció de Irma Seidler por análogas circunstancias. (Lukács, 2015b: 169). Baste recordar que Lukács tuvo contacto con la obra de Kierkegaard muy poco tiempo antes del suicidio de Irma (1911). El 25 de mayo de 1910 Lukács anota en el Diario 19101911: «también se dan otros buenos augurios: las cosas llegan a su tiempo... y hoy justamente cuando estaba reflexionando acerca del racionalismo antirracionalista - dos nuevos tomos de Kierkegaard» (Lukács, 1985a: 86). Otra forma de afrontar la pregunta que se hace Lukács consistiría en que Dios permanece como mero espectador en los asuntos humanos, asuntos que adquieren el carácter de drama cuando son llevados a las tablas por los hombres, tablas en las cuales «las relaciones entre los hombres no pueden contener nada que no esté ya contenida rigurosamente en el complejo del drama» (Lukács, 2013: 200). La figura del ser supremo siempre ha jugado un papel central en el desarrollo tanto de la tragedia como del drama. Paul Ernest, Lukács e Ibsen lo han visto. Para Lukács los dioses: 
No quieren ser solo espectadores de su consumación, directores y consumadores de ella. Traviesamente penetran sus manos en la enigmática intrincación de los hilos del destino y los revuelven hasta que ya es imposible dominarlos con la vista... Dios tiene que abandonar la escena, pero tiene que seguir siendo espectador: esta es la posibilidad histórica de la era trágica (Lukács, 2013: 244).

El cuadro de Tintoretto, La Crucifixión en la Scuola di San Rocco, sería una obra paradigmática en este sentido (Kadarkay, 1994: 754). Dios elevado en las alturas y separado definitivamente de la esfera humana. Pero para nosotros el enfrentamiento sería entre la libertad y las fuerzas ciegas de la naturaleza. Esa es una de las principales fuentes de donde bebe la tragedia: ser esclavos de fuerzas desconocidas y por ignorancia estar sometidos a ellas. Romper con esa cadena alienante es quizás una de las maneras en que el hombre puede por fin descorrer el velo que pesaba sobre su existencia y ser así dueño de esa naturaleza que siempre ha visto como opuesta y hostil. En el caso del arte, entendido como actividad creadora emancipadora, sería una herramienta útil para detener el poder de esas fuerzas oscuras y hostiles. Cuando Monteverdi hace pronunciar estas palabras al personaje que encarna a la música en su magnífica ópera L'Orfeo está siendo inequívocamente portador y difundidor de esta gran e importante tradición: "Ahora, mientras alterno mis canciones, ora alegres ora tristes, que ni un pajarillo se mueva entre estos árboles, ni de las aguas óigase rumor en estas riberas y que toda brisilla detenga su camino» (L'Orfeo. Fílmico). Parad que ha llegado el hombre. Desde luego que el panorama ha cambiado a lo largo del tiempo. Para Martínez este sería el aspecto que tendría hoy:

El genio se democratiza y los criterios valorativos se diluyen, todo vale en un arte trivializado que no es el depósito de lo sublime, como era en el romanticismo e incluso en el vanguardismo de principios de siglo, si no un artículo más de consumo que se compra, se utiliza y se tira. El arte se hace híper-realista en su fantasmagoría: ya no representa los ideales culturales de la humanidad, sino que refleja, sin tensión alguna, el sinsentido de la vida cotidiana; produce más la identificación instintiva que el distanciamiento crítico racional (Martínez, 2011: 479).

De esta ambigüedad presente entre varios fenómenos, el poder de lo sobrenatural y la posterior alienación y falta de sentido en el acto de producción y actividad humana, es en donde la tragedia tiene el filón del que extrae el valioso material de sus creaciones. Material que sería ineficaz si fuera utilizado dentro 
de un ámbito en el que, a través de la ciencia y el arte, el hombre se apropiara de la realidad material. Quedando de este modo relegado a un segundo plano el mundo metafísico y pasando a ocupar el primer lugar las actividades humanas que están encaminadas a ser las verdaderas guías en esa oscura realidad que siempre parece escaparse. Solo cuando el hombre consiga realizar ese giro podría decirse que no solo se extinguirá la necesidad religiosa, sino también, y porque no, la necesidad del drama (J. M). Entendiendo a éste como un modelo en el que se representa la gran tragedia humana:

La necesidad religiosa no puede extinguirse más que cuando el hombre consiga convertir en elementos con sentido de una vida cismundana con sentido, todas las energías espirituales y anímicas que hasta ahora no han podido vivirse más que de forma religiosa (Lukács, 1967: 576).

\section{Relaciones entre el drama y el público}

«El hecho de que el drama y el teatro están separados entre sí y que el teatro verdaderamente nuevo solo subsiste como ideal, como algo que debía ser realizado, pero que no pudo serlo» (Lukács, 1968a: 254). Para Lukács «en realidad ya no existe una auténtica masa... [quizás como público]. El teatro moderno únicamente se deja imponer al gran público a costa del precio de grandes luchas» (Lukács, 1968a: 245). Según Hauser, «el teatro adecuado a las verdaderas necesidades espirituales, y la ambición de crear un "teatro de masas" para las masas, que existían, efectivamente, pero no constituían un público teatral» (Hauser, 1962: 381). Así es que no se trataba solamente de hacer grandes esfuerzos para alcanzar al nuevo público, sino también, y por qué no, que ese público existía, pero no formaban un público como tal. El público moderno quiere un teatro $-\mathrm{y}$ en general cualquier representación artística- en el que las cosas esenciales estén mezcladas con otras para así poder digerirlas con más tranquilidad. Por el contrario, en el teatro antiguo el público se adaptaba a las pretensiones que tenían los dramaturgos, con lo que las obras no tuvieron que sufrir este tipo de mutación.

La situación de drama y público... [Lukács dice que] no sabemos cómo era el público de los dramas atenienses, pero, aunque haya sido el mejor que se pueda suponer, sabemos en cambio que el Edipo de Sófocles no salió vencedor en la competición (Lukács, 1968a: 257). 
Desde luego que estas nociones están siendo dirigidas contra la simpleza en la que se encuentra la época contemporánea, en donde la gente ya no busca el contenido de las cosas en grandes entramados dramáticos o en complejas composiciones artísticas. Aunque seguimos siendo una sociedad de la imagen -el cambio biológico se dio hace mucho tiempo, antes éramos una especie del olfato- (Gómez, 2014: 312). Lo que nos atrae es una imagen que se pueda comprender inmediatamente y así poder pasar a la siguiente. Esto guarda una estrecha relación con eso que Hegel llamó la disolución de la forma artística romántica, en la que la excesiva presencia del artista en la obra y la refiguración de los objetos de la vida cotidiana, acarreó la desaparición del arte romántico (Hegel, 2006: 361). Hoy nos encontramos con escenarios diferentes en donde el autor de los dramas no se ve en la necesidad de ser refrendado por el público, lo que a su vez produce una hipotética pérdida de calidad de lo representado.

Ante todo, hay que decir que hoy la lucha ya no es tan inevitable, hoy, es decir, desde que existe el nuevo drama (existe el drama en forma de libro, lo que no existió antes). Hoy incluso el escritor que percibe la vida necesariamente en forma dramática tiene la posibilidad de crear sin tener que considerar el escenario (Lukács, 1968a: 258).

Y así llegamos a la preocupante conclusión que entre el autor y el público se ha generado una barrera natural que impide que una obra sea valorada de acuerdo con las necesidades sociales que tiene que suplir o bien demandar. Es el público el agente más indicado para decir si una obra representa sus necesidades o no. Lukács nos pone ante la evidencia que:

El libro confiere al drama la posibilidad de prescindir del efecto inmediato sobre las masas, del efecto sobre el hombre individual. Es decir, el efecto puramente individual en vez del general, el diferenciado en vez del primitivo, el íntimo y ambiental en vez del sonoro y monumental, el intelectual en vez del sensible, el paulatino en vez del vehemente e inmediato (Lukács, 1968a: 259).

Esto produce varios efectos sobre las creaciones artísticas contemporáneas. Quizás el más llamativo sea la pérdida del compromiso que tiene que haber entre las obras y la sociedad y en la que supuestamente el artista es el intermediario, ya que al parecer es el único que está dotado de esa ¿mágica? capacidad de ver detrás de donde los ojos de un simple mortal no alcanzan a llegar con su vista. Otro efecto que se da ante este novedoso fenómeno de presentar las obras en un 
formato que no sea el escenario sería que «el drama huye como drama editado puramente lírico y filosófico ante cualquier lucha con la realidad, y que busque en parte un escenario imaginario" (Lukács, 1968a: 259). Aquí nos encontramos ya ante algo mucho más preocupante, se trata de esa huida o el rechazo de enfrentarse con la realidad. Estaríamos hablando de la interioridad o de lo que Lukács llama: «la singularidad privada» (Lukács, 1967: 325). Como se puede ver, el poder de las tendencias idealistas sigue estando muy vigente en todos los campos de la cultura, pasando a ocupar el puesto de la siempre sospechosa intelectualidad: «La cultura sobre la cual nace el nuevo drama es más intelectual que cualquier anterior» (Lukács, 1968a: 259).

El anhelo de un teatro que no solo tuviese significación para la masa cuyos deseos se limitaban a la distracción momentánea [...] coadyuvó a producir un nuevo teatro, el teatro de la minoría, el nuevo teatro íntimo. Strindberg plantea por primera vez esta idea en su prólogo a la señorita Julia, a la manera de un programa (Lukács, 1968a: 261).

Otro aspecto importante que destacar, aparte de la intelectualidad, es la ambivalencia que se presenta entre las obras de artistas que no destacan especialmente por sus inclinaciones políticas o filosóficas. Es por esto por lo que:

Lo mismo que Engels defendía el valor literario de Balzac, a pesar de su ideología conservadora, Lenin defiende la obra de Tolstoi, a pesar de su ideología retardataria y mística. Y esto en nombre del realismo. "Tolstoi es grande como intérprete de las ideas y de los estados de ánimo de millones de campesinos rusos en visperas de la revolución burguesa en Rusia" (Domínguez, 2010: 94).

Como queda puesto de manifiesto por ambos autores, no es necesario que la obra en su totalidad tenga que estar nutrida por los elementos sociales que son las que les dan origen. No siempre los autores están en condiciones de realizar dicha tarea, los motivos son múltiples. Lo más importante es que cuando lo hagan estén realizando a su vez una labor no solo educativa sino también cognitiva. Este es el caso, por ejemplo, de Los Campos Roturados y El Don Apacible de Shólojov o La Madre de Gorki, obras que reflejan fielmente la problemática social que se estaba gestando en el interior de la sociedad que, no solo les dieron origen, sino que además las hicieron nacer y, lo más importante, sociedad que ayudaron a transformar, llegando así a cumplir la gran misión para la que es creada una obra de arte. 


\section{Periodicidad y dinero}

Shakespeare ha sabido ver lo negativo del dinero y la mala influencia que ejerce sobre las personas. Por ese motivo es que tanto Marx como Lukács vuelven nuevamente a él en busca de apoyo. Ahora se trata de ver cuáles son las consecuencias que tiene el afán de conseguir dinero en nuestra sociedad. Para Lukács "Satanás aparece como la simple encarnación de la animalidad del hombre, del ansia muda de oro y sexo» (Lukács, 1967: 534-535) (J. M). En otro lugar siguiendo a Marx apunta:

Desde el punto de vista ontológico, el dinero se convirtió en tal a partir de los actos de permuta... los antiguos aún no eran capaces de llegar a esta explicación ontológica, podrá encontrar usted, desde Homero y Sófocles, constantes lamentaciones elegíacas respecto a una potencia mítica que penetra en la sociedad y se arroga un dominio sobre los hombres, pese a tratarse de un material muerto (Holz et al., 1971: 25).

El arte verdadero es el que se aleja de estos intereses, logrando así un mayor acercamiento a la esfera humana. En este sentido el arte moderno sufriría de algún tipo de deformación al buscar precisamente la complicidad de la esfera económica.

Todo buen arte y toda buena literatura es también humanista en la medida en que no solo estudia apasionadamente al hombre, la real esencia de su constitución humana, sino que, además, defiende apasionadamente la integridad humana del hombre contra todas las tendencias que la atacan, la rebajan o la deforman (Lukács, 1966a: 240).

Todas esas deformaciones y ataques a la integridad humana Lukács las ve en el capitalismo, sistema en el que el hombre es visto solo como un medio para alcanzar un fin, esto es, la riqueza. Para Lukács «todo artista auténtico, todo escritor auténtico es un enemigo instintivo de una tal violentación del principio humanista» (Lukács, 1966a: 240). Marx parte de las orientaciones tanto de Goethe como de Shakespeare para subrayar esa acción antihumana del dinero, que a la postre se convierte en acción deformadora e invasora de la esencia humana. En este aspecto veamos dos propiedades que destaca Shakespeare del dinero.

$1^{\circ}$. El dinero es la divinidad visible, la transformación de todas las propiedades humanas y naturales en su contrario, la confusión y deformación 
universal de las cosas; el dinero causa imposibilidades. $2^{\circ}$. Es la prostituta universal, el universal alcahuete de hombres y pueblos (Lukács, 1966a: 240241).

Cosa diferente ocurre cuando miramos las enseñanzas de una pequeña obra como El destino de un hombre de Shólojov (J. M.), obra en la que se muestra no solo un distanciamiento de las tendencias antes mencionadas, sino que nos instruye en sentido contrario. Esto es, muestra una total oposición a la deformidad y el alejamiento de lo humano que envuelve en parte al arte contemporáneo con su apego a lo meramente superficial y banal. En ella su protagonista Solokov, una vez le ha sido perdonada la vida por su valentía como soldado y le ha sido entregado un trozo de pan y de tocino, llega a la barraca en la que está detenido junto con un grupo de compańeros en donde uno de ellos dice:

“CCómo vamos a repartir los víveres?”, me preguntó uno de mis compañeros de camastro, y la voz le temblaba. "A todos por igual", contesté yo... cortamos el pan y el tocino, midiéndolo rigurosamente con una cuerda, en porciones idénticas. A cada uno le correspondió un pedazo de pan del tamaño de una caja de cerillas, calculando hasta las migajas, y en cuanto al tocino, ya te puedes figurar, lo suficiente para untarse los labios. Sin embargo, lo repartimos todo sin que nadie se ofendiera (Shólojov, 1962: 31).

No sería muy arriesgado decir que siguiendo las enseńanzas de Shólojov la superación de la tragedia estaría un poco más cerca.

La periodicidad en la que se encuentra el teatro y el drama en la actualidad es otro aspecto tratado por Lukács. Él ve en ella uno de los aspectos negativos de la creación artística y así lo deja de manifiesto en su Estética cuando dice:

Que le parece importante echarle un vistazo al proceso total de la creación artística. Lo esencial en él es la irrepetibilidad. Por grande, pues, que sea la capacidad técnica de un artista (y tiene que serlo), la esencia de lo estético le obliga en cada obra a empezar de nuevo a recibir y reproducir la realidad como si antes no hubiera visto nada ni dado forma a nada (Lukács, 1967: 125).

De ahí el reproche ante la repetición de un fenómeno que se va convirtiendo con el tiempo en carente de sentido. Lukács menciona a Bayreuth y lo pone como uno de los motivos que han empujado al drama a esa esterilidad que será 
la culpable en última instancia de la decadencia a la que llegó la música y gran parte del arte en el período final del romanticismo, sin negar desde luego que también produjo grandes obras de arte para el disfrute de toda la humanidad. En este sentido basta con mencionar que, según el propio Wagner, con él acaba la ópera tradicional y da comienzo lo que él mismo llamó el drama moderno: "Yo no escribo óperas, escribo dramas musicales» (Palmer, Fílmico). Esta misma idea queda reflejada en la serie fílmica La vida de Verdi cuando éste afirma: «yo no me dedico a componer fragmentos o arias, yo compongo... yo compongo un drama, un drama musical» (Castellani, Fílmico). Drama en el que se ponen en escena elementos nuevos que suplantan en parte a la ya moribunda forma de ver ópera. Es en este momento que se introduce el ya célebre Leitmotiv, el cual no es más que la repetición incesante del mismo estribillo a lo largo de toda la obra, convirtiéndose en la periodicidad artificialmente cultivada por excelencia. En esta misma línea, Thomas Mann lo deja muy claro en su gran novela El Doktor Faustus, cuando dice utilizando evidentemente los elementos que ha desarrollado Lukács tanto en El alma y las formas como en su Estética:

Pero observando lo que ocurre en la Música, y más particularmente en las últimas fases de su evolución, se descubre en ella un ansia secreta de volver a esa primitiva situación...reside en la naturaleza misma de ese arte extraordinario la capacidad de empezar de nuevo en todo momento, de descubrir y de volver a crear otra vez, partiendo de la nada, lo que ha sido logrado en el curso de una historia de siglos de cultura (Mann, 2009: 93).

\section{De Ibsen a Tolstoi y Dostoievski y luego a Shólojov y Makárenko}

Llega el momento en el que los referentes anteriores pasan a ser reemplazados por otros. Lukács no iba a ser una excepción en este caso. Pero hay que destacar que dichos cambios tuvieron varias motivaciones. Entre ellas las más importante era la esterilidad creativa que se estaba presentando dentro del seno de la moribunda sociedad burguesa, la cual, en el fondo, se oponía al progreso en el desarrollo de las creaciones artísticas, entendiendo estas como las que tenían que darle forma a la nueva clase social en ascenso, esto es, a la clase de los trabajadores. De ahí que el nuevo faro que iluminó desde la distancia a los intelectuales que pedían una nueva ruta fuera el espíritu revolucionario y el misticismo ruso de Tolstoi y Dostoievski. Löwy hace un recorrido por lo que podríamos decir es una parte de 
la evolución de las inclinaciones y preferencias literarias de Lukács (Löwy, 1978a: 260 y ss.). Entre las que destacan tanto Homero, Ibsen como Dostoievski. El cambio más significativo tiene que ver con el salto que da Lukács desde la gran figura clásica de Homero, pasando por Dante, de ahí a las dos importantes figuras de Cervantes y Rabelais, para pasar a Flaubert, Goethe, Balzac y de ahí a la enorme figura de Tolstoi, para llegar finalmente al nuevo Homero: Dostoievski. Los aspectos éticos están también involucrados en este cambio, ya que Lukács creyó encontrar en la bondad de los personajes de Dostoievski un revulsivo moral para sus propios problemas: dotar de un nuevo estatuto ético a la revolución bolchevique o afrontar la muerte de su amiga Irma Seidler.

Para poder apreciar con claridad cuáles eran las nuevas motivaciones que estaban actuando ahora en otra dirección, Löwy nos anuncia que de lo que ahora se trataba era de «esclarecer...el diálogo y la problemática anticapitalista romántica que constituía en ese momento (1910-1912) el fundamento ideológico último de la Weltanschauung (visión del mundo) de Lukács» (Löwy, 1978a: 114). Lukács se encontraba en un momento de su vida que le debió de resultar muy difícil de llevar. Recordemos que es la época en la que participa del advenimiento del neokantismo, recibe clases de Windelband y Rickert en Heidelberg, también se acerca a Dilthey y al sociologismo neokantiano de Simmel. Dentro de esta vorágine se estaba nada más y nada menos que divorciando del autor dramático del que se había alimentado en su juventud. Todo esto estaba ocurriendo con la ya opaca y menguada figura de Strindberg y Shakespeare.

Es por tal razón por lo que buscaba constantemente tendencias éticas, ya sea en el presente, ya en el pasado, que pudieran satisfacer exigencias del anticapitalista todavía romántico que yo era entonces. He aquí por qué llegué a remplazar a Ibsen -el ideal de mi período de joven crítico- por Tolstoi, y más todavía por Dostoievski (cit. en Löwy, 1978a: 114). 


\section{Conclusión}

El contenido de este artículo gira en torno a las diversas interpretaciones del drama y a las consideraciones del Lukács joven contrastadas con el Lukács maduro. Lukács siempre fue consciente de las contradicciones contenidas en sus obras, no quiso eliminarlas nunca para que quedaran como testimonios del camino recorrido. Todos los aspectos tratados en el texto fueron recogidos por Lukács en su período premarxista. La importancia de los mismos descansa sobre el soporte de que luego fueron, no solo rebatidos sino superados, como solo puede ocurrir en un pensamiento que termine regido por la dialéctica. De ahí la importancia de los mismos, ya que, sin pretenderlo, sirvieron para demostrar el mecanismo filosófico que iba a defender en un futuro ya plenamente marxista. En primera instancia, está el rechazo en su juventud a aceptar la conexión entre los fenómenos artísticos y las relaciones de producción que les dieron origen. En este sentido, es de común acuerdo incluso entre los no marxistas aceptar esta premisa ineliminable del panorama ontológico y antropológico, ya que todos los fenómenos están indisolublemente unidos a la interacción del hombre con la realidad.

Una de las nociones abordadas más importantes es la que tiene que ver con la crítica que emprende Lukács hacia la burguesía, dicha crítica es tomada directamente de Ibsen. De este autor también extrae los primeros conatos revolucionarios, los aspectos relacionados con la presencia de Dios en el drama, con la repetición de caracteres, etc. Hay que tener muy presente que el distanciamiento burgués que propone Ibsen y del que bebe Lukács se queda corto, ya que Ibsen no logra abrir la brecha definitiva que rompa verdaderamente con sus propios sueños pequeńoburgueses.

Luchaba ... [Ibsen] contra la moral convencional, contra los prejuicios burgueses y contra la sociedad dominante, en nombre de la idea de una libertad en cuya realización no creía él mismo. Era un cruzado sin fe, un revolucionario sin ideal social, un reformador que se convirtió finalmente en un amargo fatalista (Hauser, 1962: 385).

Será a partir de Strindberg cuando este alejamiento sea más definitivo. Este autor le aporta a Lukács los elementos que mostraron cierta pobreza en Ibsen y que muestran ya un acercamiento a la concepción dialéctica de la sociedad. Strindberg hace unos aportes referentes a la noción de personaje que guardan una 
afinidad muy grande con las futuras concepciones sobre el mismo desarrolladas por Lukács en su Estética. Dice Strindberg en su prólogo a La señorita Julia en 1888:

[Un personaje es el]... producto de las circunstancias, de la herencia, del ambiente, de la educación, de la disposición natural, de las influencias de lugar, la estación y la casualidad, y cuyas decisiones no tenían un motivo único, sino toda una serie de motivos (Hauser, 1962: 381).

En lo relacionado con la influencia ejercida por Shakespeare, lo más destacado sería hacer alusión a que Lukács vio en él la génesis de la teoría del reflejo (Lukács 1966a, 245). Sin olvidar sus aportes relacionados con las malas influencias del dinero y sus valiosos comentarios referentes al cambio social que se estaba dando en la época, que supo muy bien ver Shakespeare. Recordar que la obra de Shakespeare se estaba desarrollando en uno de los cambios de época más importantes que se han presentado en la historia de la humanidad. Fue el momento en el que después del Renacimiento se originaron otros dos episodios históricos sumamente importantes para la cultura humana, el Barroco y el Manierismo.

En términos generales podría decirse que las influencias que recibió Lukács fueron fundamentales para el posterior desarrollo de su obra. Sin el acercamiento que mostró hacia estos personajes no hubiera sido posible el desarrollo de la obra posterior, que ya realizó desde el gran faro del materialismo tanto histórico como dialéctico. De ahí la gran deuda que tiene la obra lukácsiana con los dramaturgos nombrados en este artículo. El paso de estos primeros autores a otros de igual calado filosófico será estudiado en un futuro trabajo de investigación. 


\section{Bibliografía}

Adorno, Theodor (2003). Filosofía de la nueva música, Madrid: Akal.

- (2008). Monografias musicales, Madrid: Akal.

- (2004). Teoría estética, Madrid: Akal.

Aristóteles (2006). Poética, Madrid: Alianza.

Domínguez, José (2010). Introducción a la teoría literaria, Madrid: Ramón Areces.

Duby, Georg (2007). Atlas histórico mundial, Barcelona: Larousse.

Feo DE, Nicola (1972). Weber-Lukács, Barcelona: A. Redondo Editor.

Freud, Sigmund (2010). El malestar en la cultura, Madrid: Alianza.

Goldmann, Lucien (1975). Para una sociología de la novela, Madrid: Editorial Ayuso.

Gómez, Carlos (2014). Freud y su obra, Madrid: Biblioteca Nueva.

Gorki, Máximo (1975). La Madre, Moscú: Editorial Progreso.

Hauser, Arnold (1967). Historia social de la literatura y el arte, Madrid: Guadarrama.

- (1979). Conversaciones con Lukács, Barcelona: Guadarrama.

HegeL, G. W. F. (2006). Estética, Madrid: Abada.

Holz, Hans Heinz et al. (1971). Conversaciones con Lukács, Madrid: Alianza.

Infranca, Antonino y Miguel Vedda (2004). Testamento político: György Lukács, Buenos Aires: Herramienta.

Infranca, Antonino (2005). Trabajo, individuo, historia, Buenos Aires: Herramienta.

KadarkaY, Arpad (1994). Georg Lukács, Valencia: Ediciones Alfons Magnànim.

Lichтнеiм, Georg (1973). Lukács, Barcelona: Grijalbo.

LöwI, Michael (1978a). Para una sociología de los intelectuales revolucionarios, México D.F: Siglo XXI.

- (1978b). El marxismo olvidado. (R. Luxemburgo, G. Lukács), Barcelona: Ed. Fontamara.

LuKÁcs, Georg (1964). El joven Hegel, Barcelona: Grijalbo.

- (1966a). Aportaciones a la historia de la estética, México: Grijalbo.

- (1966b). Estética tomo I-II, Barcelona: Grijalbo.

- (1966c). La novela histórica, México D.F.: ERA.

- (1966d). Realismo socialista de hoy, Madrid: Revista de Occidente Tomo XIII.

- (1967). Estética tomo III-VI, Barcelona: Grijalbo. 
- (1968a). Sociología de la literatura, Barcelona: Península.

- (1968b). Goethe y su época, Barcelona: Grijalbo.

- (1969a). Prolegómenos a una estética marxista, Barcelona: Grijalbo.

- (1969b). Thomas Mann, Barcelona: Grijalbo.

- (1970). Realistas alemanes del siglo XIX, Barcelona: Grijalbo.

- (1975). La crisis de la filosofía burguesa, Buenos Aires: La Pléyade.

- (1976). Problemas sobre el realismo, Barcelona: Grijalbo.

- (1977). Materiales sobre el realismo, Barcelona: Grijalbo.

- (1984). Significado actual del realismo crítico, México D. F.: Ediciones Era.

- (1985a). Diario 1910-1911. Y otros inéditos de juventud, Barcelona: Península.

- (1985b). Historia y consciencia de clase, Barcelona: Ediciones Orbis.

- (1987). El asalto a la razón, México: Grijalbo.

- (1999). Teoría de la novela, Barcelona: Ópera Mundi.

- (2001). Dostoyevski, Murcia: Biblioteca de Caracteres Literarios.

- (2004). Testamento político, Buenos Aires: Ediciones Herramienta.

- (2005). Lenin-Marx, Buenos Aires: Ediciones Gorla.

- (2011). Escritos de Moscú, Buenos Aires: Ediciones Gorla.

- (2013). El alma y las formas, Valencia: Universitat de València.

- (2014). Táctica y ética. Escritos tempranos (1919-1929), Buenos Aires: Herramienta.

- (2015a). Derrotismo y Dialéctica, Buenos Aires: Herramienta.

- (2015b). Acerca de la pobreza de espiritu, Buenos Aires: Ediciones Gorla.

- (2017). Falsa y auténtica Ontología de Hegel, Barcelona: Edicions Bellaterra.

Mann, Thomas (2009). Doktor Faustus, Barcelona: Edhasa.

Martínez, Francisco José (2008). Hacia una era post-mediática, Barcelona: Montesinos.

- (2011). Metafisica, Madrid: UNED.

Marx, Karl (1975). El Capital, México D.F: Fondo de Cultura Económico.

- (2010). La ideología alemana, Buenos Aires: Losada.

Muñoz, Jacobo (2010). Filosofía de la historia, Madrid: Biblioteca Nueva.

Parkinson, G. H. R. (ed.) (1973). Georg Lukács, Barcelona: Grijalbo. 
Piana, Giovani (1978). El joven Lukács, México: Cuadernos de Pasado y Presente, Siglo XXI.

Raddatz, Fritz J. (1975). Georg Lukács, Madrid: Alianza.

Ruiz, Rene (1976). Lukács: Teoría Literaria, Madrid: Las Américas.

Sánchez Meca, Diego (1996). Diccionario de filosofía, Madrid: Alderabán.

Shólojov, Michael (1962). El destino de un hombre, Buenos Aires: Quetzal.

SuRGHI, Carlos (2015). Qué es el ensayo. "Forma, romanticismo y negatividad en el joven Lukács”, Buenos Aires: el cuenco de plata.

\section{Fílmico}

La vida de Verdi. Dir. Renato Castellani. Producida por la RIA. Euromedia visión. 2010. Fílmico.

L'Orfeo. Claudio Monteverdi. Deutsche Grammophon, 2006. Ópera. Fílmico.

Wagner la historia épica de un músico enigmático y genial. Dir Tony Palmer. Act. Richard Burton, Vanessa Redgrave, Sir John Hielgud, Sir Laurence Olivier. RM Associates, 1982. Fílmico.

RECIBIDO: 2I/II/2OI7

Aceptado: I6/04/2018

Este trabajo se encuentra bajo una licencia de Creative Commons Reconocimiento-No Comercial-SinObraDerivada 4.0 
